University of Nebraska - Lincoln

DigitalCommons@University of Nebraska - Lincoln

$11-6-2018$

\title{
Seasonality of Life History Events and Behavior Patterns in the Island Endemic Hawaiian Duck (Anas wyvilliana)
}

Christopher P. Malachowski

Bruce D. Dugger

Kimberly J. Uyehara

Follow this and additional works at: https://digitalcommons.unl.edu/usfwspubs

This Article is brought to you for free and open access by the US Fish \& Wildlife Service at DigitalCommons@University of Nebraska - Lincoln. It has been accepted for inclusion in US Fish \& Wildlife Publications by an authorized administrator of DigitalCommons@University of Nebraska - Lincoln. 


\title{
Seasonality of Life History Events and Behavior Patterns in the Island Endemic Hawaiian Duck (Anas wyvilliana)
}

\author{
Christopher P. Malachowski ${ }^{1, *}$, Bruce D. Dugger ${ }^{1}$ and Kimberly J. Uyehara ${ }^{2}$ \\ ${ }^{1}$ Department of Fisheries and Wildlife, Oregon State University, 104 Nash Hall, Corvallis, Oregon, 97331, USA
}

${ }^{2}$ U.S. Fish and Wildlife Service, Kaua ‘i National Wildlife Refuge Complex, P.O. Box 1128, Kilauea, Hawai‘i, 96754, USA

*Corresponding author; E-mail: christopher.malachowski@oregonstate.edu

\begin{abstract}
Year-round behavioral observations and surveys were used to investigate the temporal dynamics of life history events and associated variation in behavioral activities of the endangered, island-endemic Hawaiian Duck (Anas wyvilliana) on Kaua'i, Hawai'i, USA. Although breeding activity occurred throughout the year, backdated brood observations $(n=67)$ revealed that birds initiated 94\% of nests during the 9-month period from September through May, their peak nesting season. A greater proportion of females $(n=149)$ were paired during the peak nesting season $(75 \%)$ than the off-peak season (48\%). Behavioral patterns $(n=984 ; 329 \mathrm{hr})$ differed between seasons for males but not for females. Males allocated more time to vigilance and less time to foraging during the peak nesting season than the off-peak season. Activity budgets also differed between sexes, but only during the peak nesting season. During this period, females spent more time foraging than males, whereas males allocated more time to vigilance, locomotion, and social activities. Current management objectives for the Hawaiian Duck aim to provide resources for multiple life history stages concurrently throughout the year, and although this approach is largely appropriate, our results suggest refinements in the timing of certain activities (e.g., managing nesting habitat to be available during September-May). Received 13 September 2018, accepted 6 November 2018.
\end{abstract}

Key words.-Anas wyvilliana, annual cycle, behavior, brood observations, Hawaiian Duck, nesting, pair formation, seasonality, time-activity budgets, waterfowl.

Waterbirds 42(1): 78-89, 2019

The Hawaiian Duck (Anas wyvilliana) is a non-migratory, monochromatic dabbling duck and the only endemic duck species remaining in the main Hawaiian Islands, USA. Closely related to the Mallard (A. platyrhynchos) and Laysan Duck (A. laysanensis) (Lavretsky et al. 2015), the Hawaiian Duck has experienced range contraction and population declines because of factors that include habitat loss, introduced predators, overharvest, and hybridization with feral Mallards (Uyehara et al. 2008; Fowler et al. 2009; U.S. Fish and Wildlife Service 2011). Consequently, the Hawaiian Duck is listed as endangered by the U.S. Fish and Wildlife Service and the International Union for Conservation of Nature (U.S. Fish and Wildlife Service 2011; BirdLife International 2017). Recovery efforts for the species have been hindered by the paucity of information on many fundamental aspects of its biology and behavior, such as the temporal dynamics of its life history events and associated seasonal variation in behavioral activities (e.g., foraging effort; Engilis et al. 2002).

The timing of annual life history events for migratory waterfowl breeding in temperate and Arctic regions has been well- studied (Baldassarre 2014), but these temporal patterns may not necessarily apply to non-migratory, tropical species such as the Hawaiian Duck. At temperate and Arctic latitudes, strong and predictable seasonal variation in climate and photoperiod generally results in one period of peak food availability each year. Holarctic migratory waterfowl therefore synchronize the timing of migration and breeding to coincide with these environmentally favorable conditions (Immelmann 1971; Oring and Sayler 1992; Williams 2012). By comparison, tropical ducks are generally more sedentary (Weller 1980; Newton 2008; Baldassarre 2014) and experience more stable climate, milder temperatures, and often year-round resource availability (Stutchbury and Morton 2001). Further, peaks in resource abundance (e.g., invertebrates, seeds) may be subtle or irregular at tropical latitudes (Karr 1976; Hails 1982; Coffman and de la Rosa 1998; Jacobsen et al. 2008). These differences in climate and resources often result in longer breeding seasons, more out-of-season breeding, and reduced synchrony in life history events (Immelmann 1971; Wyndham 1986; 
Stouffer et al. 2013). Breeding is among the most energetically demanding of life-history activities for birds, and therefore, a better understanding of breeding phenology may help biologists focus conservation and management actions (e.g., habitat management, control of introduced predators; Batt et al. 1992).

For threatened or endangered species, quantifying behavioral patterns throughout the annual cycle is a noninvasive approach to investigating the general timing of life history events and identifying the period of the year when resources (e.g., breeding or molting habitat) may be most important. Observations of broods and nests indicate Hawaiian Ducks breed year-round (Swedberg 1967; Giffin 1983). Limited records on the Hawaiian island of Kaua'i suggest that peak nest initiation may occur between December and May (Swedberg 1967), and pair formation may peak between November and March (Swedberg 1967; Engilis et al. 2002). However, the data available for ascertaining nesting and pairing chronology are limited to either qualitative records or surveys that include unaged brood and nest sightings (Swedberg 1967; Giffin 1983; Engilis et al. 2002). Further, previous descriptions of timing patterns did not acknowledge temporal variation in survey effort (Swedberg 1967; Giffin 1983; Engilis et al. 2002), and more refined estimates with balanced sampling effort throughout the year would be valuable for management planning. Quantifying how birds allocate time to various activities on a daily and seasonal basis has been a common approach to gauge the fundamental requirements of a species (Ashkenazie and Safriel 1979; Goldstein 1988) and can provide insight into how they respond to climatic, social, and life-history factors (Caraco 1979; Paulus 1988a; Arzel et al. 2007; Jónsson and Afton 2009). Thus, more detailed information about the timing of life history events and associated changes in behavior patterns (e.g., foraging effort, courtship) would better guide Hawaiian Duck conservation and management.

In this study, we used year-round behavioral observations and surveys to identify the primary months associated with pair formation and breeding for Hawaiian Ducks, and we assessed the relative role of factors that influence annual behavior patterns. Our specific objectives were to: 1) quantify and assess patterns in key behaviors (e.g., courtship, foraging), pairing chronology, and brood sightings to assess seasonality in life-history events (pair formation, nesting); and 2) examine the effects of social, climatic, and seasonal factors on time-activity budgets. We predicted that nesting activity would be positively associated with monthly and seasonal rainfall because precipitation is often positively linked to resource availability and breeding activity for tropical and subtropical birds (Sorenson 1992; Wikelski et al. 2000; Reynolds et al. 2007; Bielefeld et al. 2010). Also, we hypothesized that females would increase foraging effort during the nesting season because of higher nutrient and energy demands associated with egg formation (Alisauskas and Ankney 1992; Krapu and Reinecke 1992), whereas males would increase time allocated to courtship, mate-guarding, and vigilance at the expense of time spent foraging during the pairing and nesting periods (Rohwer and Anderson 1988; Oring and Sayler 1992).

Methods

Study Area

We studied Hawaiian Duck behavior between September 2010 and August 2011 at Hanalei National Wildlife Refuge (NWR), in the lower Hanalei River Valley on the north shore of the island of Kaua'i, Hawai'i, USA $\left(22^{\circ} 12^{\prime} 23^{\prime \prime} \mathrm{N}, 159^{\circ} 28^{\prime} 32^{\prime \prime} \mathrm{W}\right.$; Fig. 1). The islands of Kaua' $\mathrm{i}$ and $\mathrm{Ni}$ 'ihau support over $90 \%$ of remaining nonhybridized Hawaiian Ducks (Engilis et al. 2002), and Hanalei NWR, a core wetland complex, is considered the single most important low elevation wetland site on those islands (U.S. Fish and Wildlife Service 2011). The primary cover types on this 371-ha refuge are managed seasonal wetlands and flooded agricultural fields used for the production of taro (Colocasia esculenta). Taro is a traditional Hawaiian food crop that is farmed in shallowly flooded fields, or lo'i, similar to rice paddies, and taro planting on the refuge is staggered throughout the year to allow for year-round harvest. The refuge wetlands are managed as seasonally or semi-permanently flooded palustrine emergent wetlands to benefit Hawaiian Ducks and three other endangered Hawaiian waterbird species (U.S. Fish and Wildlife Service 2011). Mean 


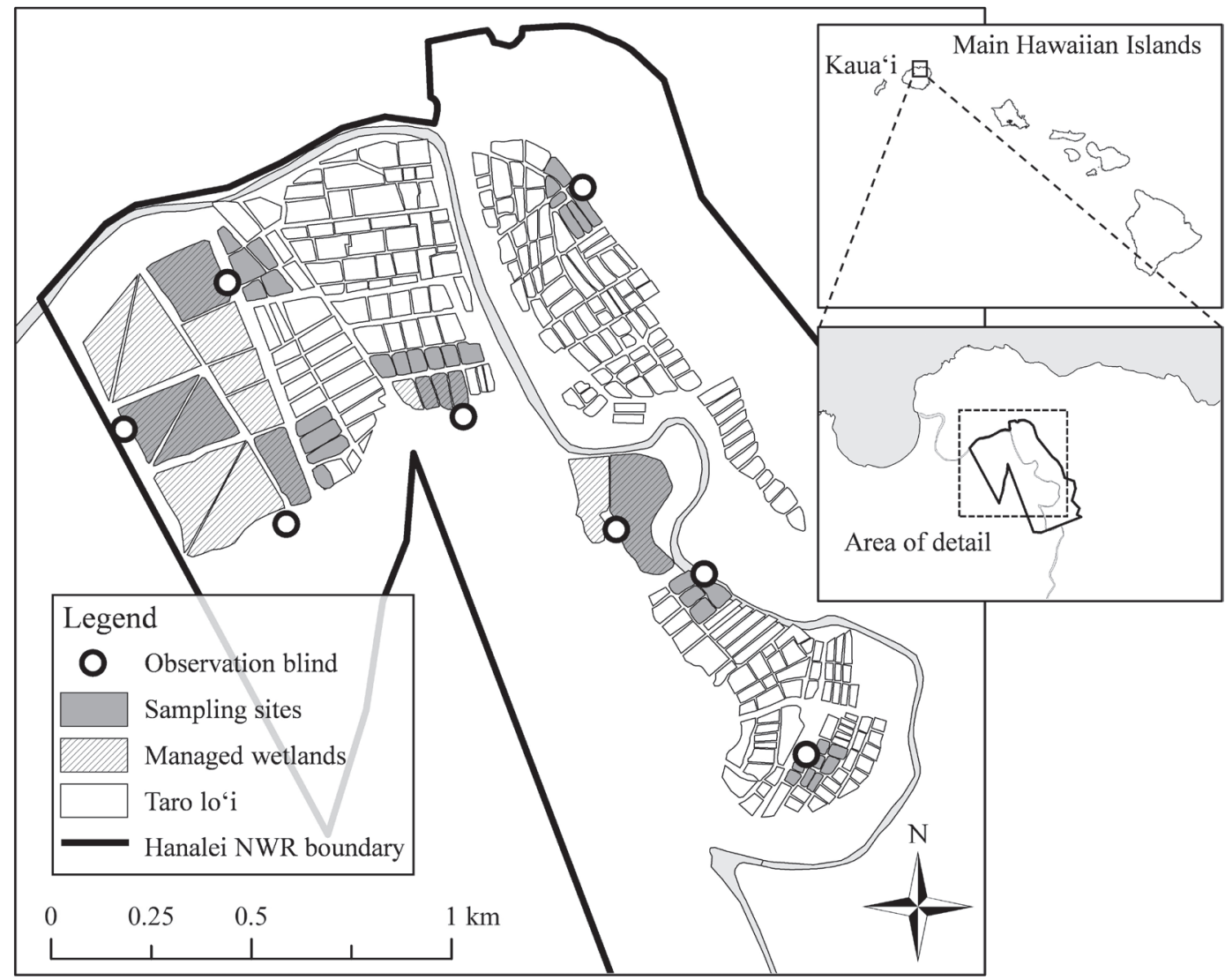

Figure 1. Hanalei National Wildlife Refuge (NWR), Kaua'i, Hawai'i, USA, with detail of distribution of managed wetlands and taro lo'i, including sampling sites, where Hawaiian Duck behavior and breeding patterns were studied from September 2010 to August 2011.

annual rainfall at Princeville Ranch (1938-2009), $1 \mathrm{~km}$ north of Hanalei NWR, is $208 \mathrm{~cm} /$ year, allocated between a wet season (November to April, $20.0 \pm 2.5$ [SD] $\mathrm{cm} /$ month) and a relatively drier season (May to October, $14.7 \pm 2.3[\mathrm{SD}] \mathrm{cm} / \mathrm{month}$ ) (National Climate Data Center 2017). Temperatures in this region (1999-2009) fluctuate little throughout the year. Mean monthly low temperatures vary from $17.1^{\circ} \mathrm{C}$ in February to $20.7^{\circ} \mathrm{C}$ in August, while mean high temperatures range from 25.7 ${ }^{\circ} \mathrm{C}$ to $29.8^{\circ} \mathrm{C}$ in February and September, respectively (National Climate Data Center 2017).

\section{Brood Observations}

We recorded brood sightings at Hanalei NWR during behavior surveys and other refuge-related activities. We estimated duckling age based on size and plumage class (Gollop and Marshall 1954). We differentiated broods based on chick age, location, and occasionally unique, physical characteristics of the adult female. For each brood, we estimated hatch date using age at first sighting, and we backdated nest initiation date (i.e., date first egg laid) assuming that the incubation period was 28 days (Swedberg 1967), the clutch size was eight eggs, which is the mean clutch size of nests found on
Kaua'i ( $n=6$; Richardson and Bowles 1964; Swedberg 1967), and the mean laying rate was one egg per day (Alisauskas and Ankney 1992).

\section{Behavioral Observations}

We selected a representative sample of managed wetlands $(n=6)$ and taro complexes $(n=6)$ from those on the study area as focal areas for collecting data on behavior (Fig. 1). The managed wetland impoundments included a variety of habitat conditions and succession stages, and the taro complexes (totaling 33 individual lo'i) spanned a range of taro ages and a diversity of taro farming styles.

We conducted surveys from eight 3-m high tower blinds positioned near the study sites. We stratified observation effort by cover type (managed wetland and taro) and time of day, which we divided equally into four periods spanning $30 \mathrm{~min}$ before sunrise to $30 \mathrm{~min}$ after sunset to assure representative sampling during daylight hours. We randomized the order of site visits and waited $\geq 5$ min after arriving at a site before beginning behavior surveys to minimize recording observerinfluenced behavior.

We randomly selected focal individuals for behavioral sampling by counting the number of birds $(i)$ at 
the survey site, obtaining a random number $(j)$ from a random number chart, and counting birds left to right until we reached the $j$ th individual. We determined the sex and age (juvenile, adult) of focal individuals using plumage characteristics (A. E. Engilis, Jr., unpubl. data). Because we could not always distinguish birds in formative and first alternate plumage (i.e., first year birds) from birds in definitive basic and alternate plumage (i.e., adults), we grouped first year birds with adults. We did not conduct focal observations on ducklings, but we sampled females with broods. We recorded pair status of focal individuals at the end of each observation session. To avoid mistaking temporary associations with being paired, we classified birds as paired only if they: 1) exhibited generally synchronized activities (particularly, locomotion); 2) maintained a close spatial relationship (approximately $\leq 3 \mathrm{~m}$ ) during most of the observation session; and 3) mutually avoided or threatened other Hawaiian Ducks when nearby (Paulus 1983). We determined pairing chronology from the percentage of focal adult females that were paired each month.

We used instantaneous focal sampling procedures (Altmann 1974) to quantify the time-activity budgets of birds between September 2010 and August 2011. We observed birds with a 20-60x spotting scope or 10x binoculars, and we recorded the behavioral activity of focal individuals at 10 -sec sample intervals for up to $30 \mathrm{~min}$ using a digital voice-activated recorder and electronic timer (Baldassarre et al. 1988; Dugger and Petrie 2000). Given that the Hawaiian Duck and Mallard are closely related (Lavretsky et al. 2015) and share a similar behavioral repertoire (Malachowski 2013), we adopted behavior terminology established for Mallards (Lorenz 1951; Johnsgard 1965; McKinney 1965). We assigned behaviors to 73 activities (Malachowski 2013); however, for most analyses, we grouped behaviors into six primary categories: foraging, resting, maintenance, locomotion, alert, and social (includes courtship and intraspecific and interspecific agonistic interactions). We recorded instantaneous behaviors as events and states, with events being occurrences of a behavior, and states occurring in a continuum (Altmann 1974). We combined behavioral states and events to determine the total proportion of time for each behavior. Since many courtship behaviors involved modified maintenance movements, we differentiated between these two states based on the orientation and proximity of focal individuals to females and males, the nature of interactions among conspecifics, and the overall context of the situation (McKinney 1965).

When focal birds moved out of sight, we recorded behavior as out of view until the individual returned into view. If the focal individual remained out of view, left the survey site, or switched cover types, and if a bird of similar sex, age, and pair status was present in the same cover type at the survey site, we continued the observation session by watching the alternate bird (Losito et al. 1989); otherwise, the session was ended. We conducted no more than one behavioral observation session per survey site per time period in a given day to maximize the independence of behavioral responses among fo- cal samples, and most (94.0\%) observation sessions at a given survey site were separated by $\geq 1$ day. We used observation sessions lasting between 5 and $30 \mathrm{~min}(\overline{\mathrm{x}}=$ $20.0 \pm 7.9 \mathrm{~min}[\mathrm{SD}]$ ) for subsequent analyses to minimize biasing samples toward more sedentary behaviors that may occur more frequently in longer sessions or more active behaviors that may occur during shorter sessions. One observer collected all data to eliminate inter-observer variation. We obtained monthly climate data (total rainfall, mean minimum and maximum temperatures) from a climate station at Princeville Ranch, approximately $1 \mathrm{~km}$ north of the refuge (National Climate Data Center 2017).

\section{Statistical Analyses}

Prior to analyses, we converted activity data to proportions of time engaged in each behavior during each focal observation session (Baldassarre et al. 1988). We used individual focal observation sessions as the sample unit to determine the relationship between dependent variables (i.e., proportion of time engaged in each behavior) and sex, pair status, and temporal variables. To explore temporal trends in behaviors, we separately tested how behaviors varied by month and season (peak vs. off-peak nesting season). We defined peak nesting season as the consecutive period during which $\geq 90 \%$ of backdated nests were initiated (based on brood observations) and off-peak nesting season as all other months. Because individual behaviors within a single focal observation sample were not independent (i.e., the proportion of time spent in one behavioral activity affects the proportion of time spent in other activities), we used factorial multivariate analysis of variance (MANOVA) using Wilks' lambda test criterion to simultaneously evaluate the effects of explanatory variables on timeactivity budgets after accounting for land cover type (Ramsey and Schafer 2002). Specifically, we conducted two MANOVAs to test if behaviors varied by season or month. We used season (peak vs. off-peak nesting) based on brood observations in the first model and month as the measure of temporal effect in the second model. We included a season-sex interaction term in the first model to test if behavioral patterns differed between seasons by sexes.

If MANOVA indicated significant effects of explanatory variables $(P<0.05)$, we used univariate analysis of variance (ANOVA) to further examine the effects on separate behaviors after accounting for land cover type. Although we tested for differences in all primary behaviors, we were particularly interested in foraging effort, vigilance, and specific social behaviors (e.g., courtship, mate-guarding, agonistic interactions) because these behaviors had relevance to understanding seasonal patterns in life history events. In each case, the specific behavior of interest was the response variable, and sex, pair status, and season (including sex-season interaction) or month were the explanatory variables. We applied logit transformations to proportions prior to analysis to improve homogeneity of variances and meet the assumption of normality for the residuals of 
the linear models (Ramsey and Schafer 2002). If logit transformations failed to normalize the residuals and satisfy the equal variance assumption for parametric testing, we used the Kruskal-Wallis test to compare the untransformed proportion of time engaged in the activity between explanatory variables (Ramsey and Schafer 2002). To assess the effect of pair status on activity budgets (MANOVA) and individual behaviors (ANOVA), we removed from analysis focal samples conducted on birds with undetermined pair statuses, juvenile birds, and females with broods.

We used Spearman's correlation analysis to examine the relationship between behavioral activities and total monthly rainfall, using mean monthly proportions of time spent in each behavior as the sample unit. In addition to total monthly rainfall, we tested for effects of lagged monthly rainfall (i.e., total rainfall during previous month), as rainfall and associated effects on habitat and resources in the preceding month could affect bird activity budgets in the current month. We also used Spearman's correlation analysis to examine the relationship between apparent nesting activity (i.e., number of nests initiated each month based on brood observations) and monthly climate variables (concurrent rainfall, lagged rainfall, mean minimum and maximum temperatures). We used a one-tailed, two-sample $t$-test to test the alternative hypothesis that nesting activity was greater during months associated with the typical wet season (i.e., November-April) based on long-term climate data (1938-2009; National Climate Data Center 2017), and we used a two-sided $t$-test to assess if the mean monthly proportion of paired, adult females differed between peak and off-peak nesting seasons. We report all time-activity budget values as untransformed means \pm standard error (SE) for more meaningful interpretation. We used the statistical software $\mathrm{R}$ to perform all statistical analyses (R Development Core Team 2017).

\section{Results}

\section{Nesting and Pairing Activity}

Between September 2010 and August 2011, we recorded 178 Hawaiian Duck brood sightings representing 67 broods. Based on backdating, birds initiated $94 \%$ of nests during the 9-month period from September through May (hereafter, peak nesting season) and $57 \%$ of nests during the 4-month period from January through April (Fig. 2). Nests were initiated in every month except June, and nesting appeared to follow a bimodal pattern with pulses during September-October and January-May. Monthly nesting activity increased with decreasing mean monthly minimum temperature, which ranged from $17.6{ }^{\circ} \mathrm{C}$ in January to $20.8^{\circ} \mathrm{C}$ in August $(r=-0.63, P=0.027)$. Total monthly rainfall varied from 6.4 to $46.7 \mathrm{~cm} /$ month and was higher and more variable between December and May $(\overline{\mathrm{x}}=22.6 \pm 13.9 \mathrm{~cm} /$ month $[\mathrm{SD}])$ than other months $(\overline{\mathrm{x}}=11.2 \pm$ $5.3 \mathrm{~cm} /$ month). Despite such variation, nest initiation was not associated with concurrent or lagged monthly rainfall $(P>0.5)$, nor with the typical wet season (i.e., November-April; $P=0.11)$.

The proportion of adult birds that were paired differed between peak and off-peak nesting season, but only for females. The

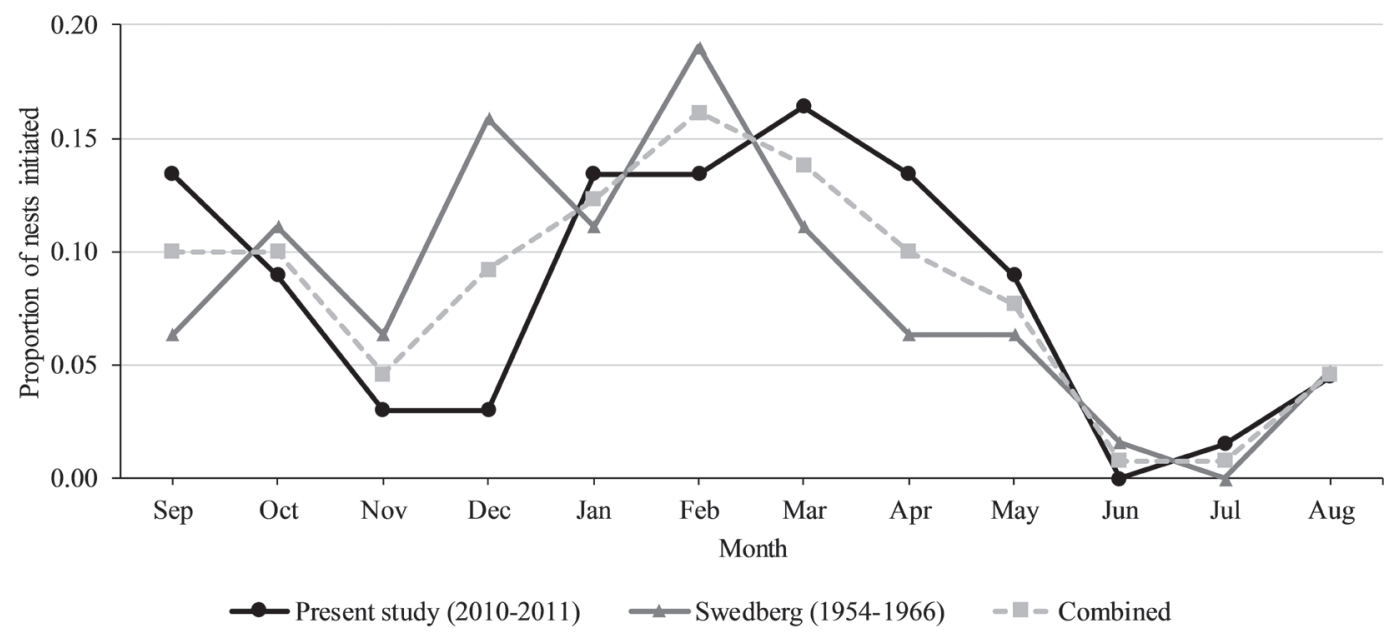

Figure 2. Monthly variation in Hawaiian Duck nest initiation dates on Kaua'i backdated from brood observations from September 2010 to August 2011 (present study; $n=67$ ) and 1954-1966 (data modified from Swedberg (1967); $n=63)$. 
mean monthly percentage of paired, adult females was $68.0 \pm 5.6 \%(\mathrm{SE} ; n=149)$, and the percentage of females that were paired was greater during peak $(74.8 \pm 4.9 \%)$ compared to off-peak nesting season (47.9 $\pm 11.5 \% ; t_{10}=2.56, P=0.029$; Fig. 3$)$. The monthly percentage of paired, adult males averaged $24.7 \pm 6.3 \%(n=557)$ and did not vary between seasons $\left(27.6 \%\right.$ vs. $16.1 \%$; $t_{10}=$ $0.78, P=0.452$; Fig. 3). Instead, the percentage of paired males peaked in September $(66.7 \%)$ and October $(72.7 \%)$ and did not exceed $26 \%$ in all other months $(\overline{\mathrm{x}}=15.7$ $\pm 1.8 \%)$.

\section{Time Activity Budgets}

We collected 984 focal samples from 224 females and 760 males totaling $329 \mathrm{hr}$ of behavioral observations. The distribution of the sample between sexes was consistent with the sex ratio of Hawaiian Ducks at Hanalei NWR (C. P. Malachowski, unpubl. data). MANOVA models indicated that activity budgets varied by sex (Wilks' $\lambda=0.97$, $F_{6,972}=5.7, P<0.001$ ), pair status (Wilks' $\lambda$ $=0.94, F_{6,695}=7.5, P<0.001$ ), season (Wilk's $\left.\lambda=0.97, F_{6.972}=4.3, P<0.001\right)$, sex-season interaction (Wilk's $\lambda=0.98, F_{6,972}=2.8, P=$ 0.010 ), and month (Wilk's $\lambda=0.89, F_{66,5158.3}=$ $1.7, P<0.001)$.
Behavioral patterns of birds differed between peak and off-peak nesting seasons for males but not for females (Table 1). Males allotted more time to alert behavior (12.6 vs. $9.2 \%)$ and locomotion (17.2 vs. $13.2 \%)$, and less time to foraging (9.9 vs. $16.3 \%)$ during the peak nesting season compared to the offpeak season. Although time spent in social behaviors did not differ between seasons for males, courtship $(1.1 \pm 0.3 \%$ vs. $0.3 \pm 0.1 \%)$ and mate-guarding activities $(0.5 \pm 0.4 \%$ vs. $<0.1 \%)$ in managed wetlands were most pronounced during November through March (Fig. 4); courtship rarely occurred in taro $(0.1 \pm 0.05 \%)$.

Season-specific patterns of behavior differed between sexes (Table 1). During the peak nesting season, females spent more time than males foraging (17.4 vs. 9.9\%; Fig. 5), whereas males allocated a greater percentage of time to alert behavior (12.6 vs. $7.9 \%)$, locomotion (17.2 vs. $9.4 \%)$, and social activities (1.2 vs. $0.3 \%)$, particularly courtship (Kruskal-Wallis, $H_{1}=6.89, P=$ $0.009)$ and intraspecific agonistic interactions (Kruskal-Wallis, $H_{1}=7.44, P=0.006$; Table 1). During the off-peak nesting season, the activity budgets of males and females were similar.

Pair status influenced the activity budgets of adult birds (Table 2). Throughout

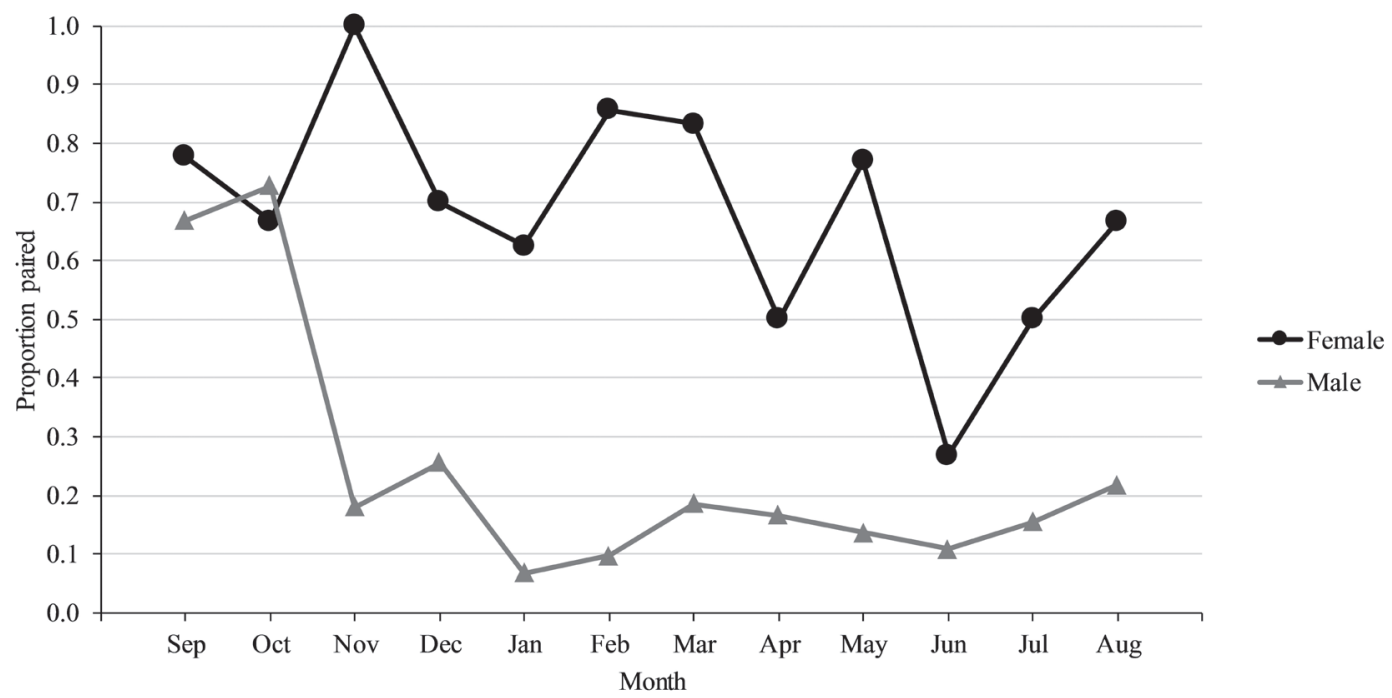

Figure 3. Monthly variation in the proportion of paired female and male Hawaiian Ducks $\left(n_{\text {female }}=149 ; n_{\text {male }}=557\right)$ at Hanalei National Wildlife Refuge, Kaua'i, Hawai‘i, USA, from September 2010 to August 2011. 
Table 1. Comparison of time-activity budgets $( \pm \mathrm{SE})$ of female and male Hawaiian Ducks $(n=984$ observation sessions) during peak and off-peak nesting seasons at Hanalei National Wildlife Refuge, Kaua'i, Hawai $i$, USA, from September 2010 to August 2011. For each behavior, analysis of variance was used to examine the effects of sex, season, and sex-season interaction after accounting for cover type and pair status, unless otherwise indicated; ${ }^{\mathrm{KW}}=$ Kruskal-Wallis tests. Superscripts indicate significant differences $(P<0.05)$ between sexes $(A)$ and between seasons (B).

\begin{tabular}{|c|c|c|c|c|}
\hline \multirow[b]{3}{*}{ Behavior } & \multicolumn{4}{|c|}{ Percent Time Spent Per Behavior } \\
\hline & \multicolumn{2}{|c|}{ Peak Nesting Season } & \multicolumn{2}{|c|}{ Off-peak Nesting Season } \\
\hline & Female & Male & Female & Male \\
\hline Forage $\mathrm{KW}^{\mathrm{k}}$ & $17.4 \pm 2.4^{\mathrm{A}}$ & $9.9 \pm 0.9^{\mathrm{A}, \mathrm{B}}$ & $17.7 \pm 3.5$ & $16.3 \pm 1.9^{\mathrm{B}}$ \\
\hline Rest & $38.9 \pm 3.0$ & $34.5 \pm 1.5$ & $34.6 \pm 3.9$ & $36.3 \pm 2.3$ \\
\hline Maintenance & $26.1 \pm 2.3$ & $24.5 \pm 1.1$ & $25.6 \pm 3.0$ & $24.2 \pm 1.7$ \\
\hline Locomotion & $9.4 \pm 1.1^{\mathrm{A}}$ & $17.2 \pm 1.0^{\mathrm{A}, \mathrm{B}}$ & $11.4 \pm 1.6$ & $13.2 \pm 1.1^{\mathrm{B}}$ \\
\hline Alert & $7.9 \pm 0.7^{\mathrm{A}}$ & $12.6 \pm 0.6^{\mathrm{A}, \mathrm{B}}$ & $10.2 \pm 1.6$ & $9.2 \pm 0.8^{\mathrm{B}}$ \\
\hline Social $^{\mathrm{KW}}$ & $0.3 \pm 0.1^{\mathrm{A}}$ & $1.2 \pm 0.2^{\mathrm{A}}$ & $0.5 \pm 0.1$ & $0.7 \pm 0.1$ \\
\hline$n$ & 147 & 542 & 77 & 218 \\
\hline
\end{tabular}

the year, paired birds foraged more $(20.3$ vs. $12.0 \%$ ) than unpaired adults. In addition, paired birds engaged in more social behavior $(1.8 \%)$ than unpaired birds $(0.7 \%)$, allotting more time to aggressive behavior toward conspecifics (KruskalWallis, $\left.H_{1}=18.6, P<0.001\right)$. Paired males allocated more time than unpaired males to alert behavior (14.1 vs. $11.0 \%$; ANOVA, $\left.F_{1,553}=3.9, P=0.049\right)$, courtship (0.9 vs. $0.3 \%$; Kruskal-Wallis, $\left.H_{1}=10.5, P=0.001\right)$, and mate-guarding (1.0 vs. $<0.1 \%$; KruskalWallis, $\left.H_{1}=45.4, P<0.001\right)$.
Generally, climate variables were not associated with variation in behavior. However, lagged monthly rainfall was positively correlated with the proportion of time birds spent foraging $(r=0.61, P=0.040)$. Concurrent and lagged monthly rainfall did not influence time allocated to other behaviors $(P>0.1)$.

\section{Discussion}

Although we observed breeding activity throughout the year on Kaua'i, our find-

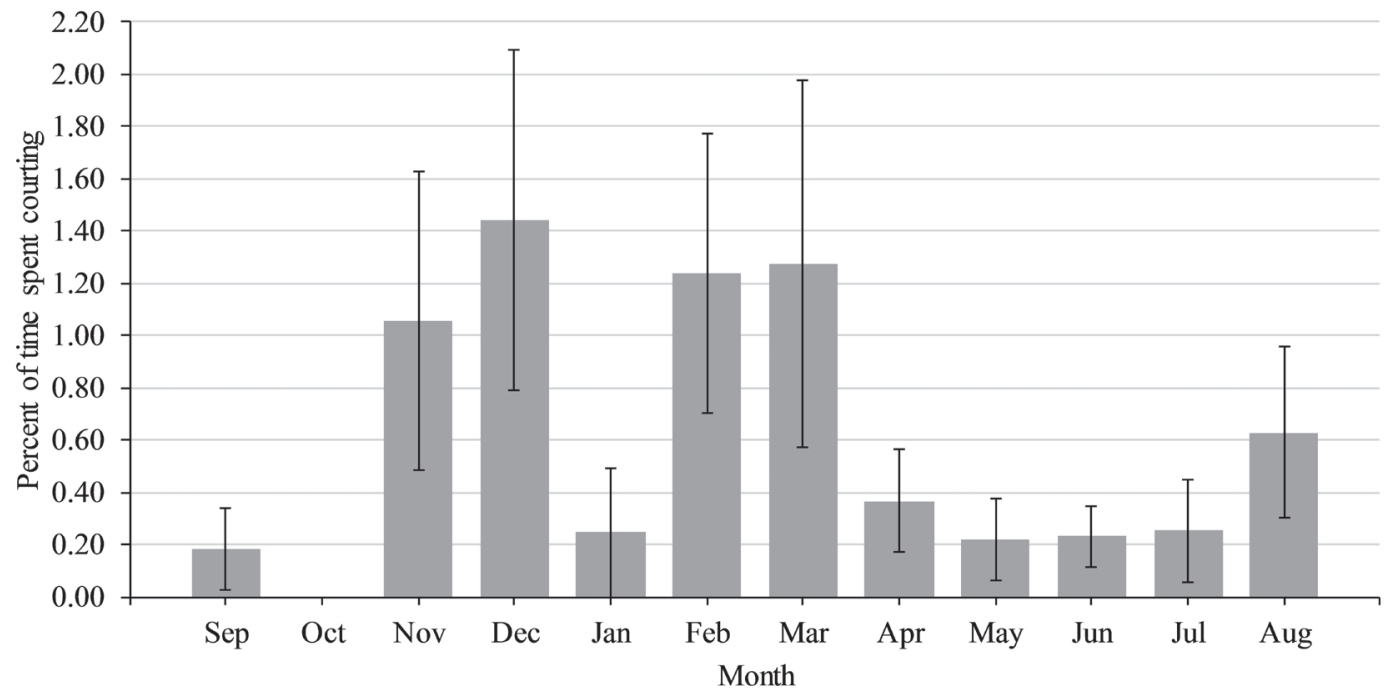

Figure 4. Monthly variation in the percent time $(\overline{\mathrm{x}} \pm \mathrm{SE})$ male Hawaiian Ducks allocated to courtship activities $(n$ = 388 observation sessions) in managed wetlands at Hanalei National Wildlife Refuge, Kaua'i, Hawai'i, USA, from September 2010 to August 2011. 


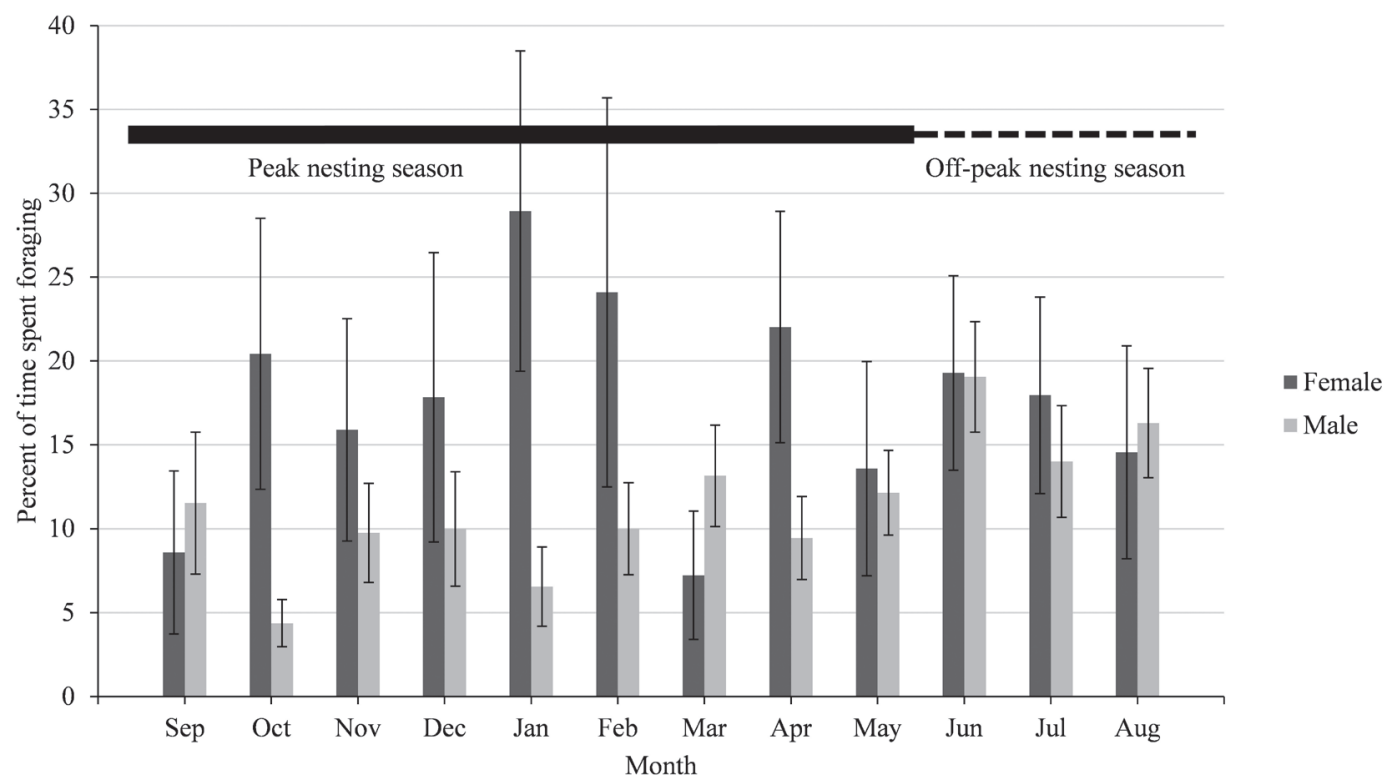

Figure 5. Monthly variation in the percent time $(\overline{\mathbf{x}} \pm \mathrm{SE})$ male $(n=760$ observation sessions $)$ and female $(n=224)$ Hawaiian Ducks spent foraging during the peak nesting season and off-peak season at Hanalei National Wildlife Refuge, Kaua'i, Hawai'i, USA, from September 2010 to August 2011.

ings indicate that Hawaiian Ducks have an extended nest-initiation season that occurs primarily during the 9-month period from September through May. The timing of nesting suggested by our brood observations corroborate earlier observations made by Swedberg (1967; Fig. 2). For comparison purposes, we estimated nest initiation dates of brood observations on Kaua'i $(n=63)$ reported by Swedberg (1967) using our backdating methods. Although nest initiation dates derived from Swedberg's observations could be over- or underestimated by more than 2 weeks, the broad pattern in nesting activity is consistent with our findings. Com- bining datasets, $94 \%$ of nest initiations occurred during the 9-month period from September through May, and $69 \%$ occurred from December through May.

Our characterization of the nesting season is further supported by patterns in the occurrence of paired birds and seasonal patterns of behavior. Peak pairing occurred during November, when $100 \%$ of focal adult females were paired, and paired females were more common during the peak nesting season $(75 \%)$ compared to the offpeak season (48\%). Consistent with our observations of pairing and nesting patterns and similar to observations of other ana-

Table 2. Comparison of activity budgets $( \pm$ SE) between paired $(n=193$ observation sessions $)$ and unpaired $(n=$ 513) adult Hawaiian Ducks at Hanalei National Wildlife Refuge, Kaua'i, Hawai'i, USA, from September 2010 to August 2011. Test statistics are $F$-values from separate ANOVAs after accounting for sex, season, sex-season interaction, and cover type, unless otherwise indicated; ${ }^{\mathrm{KW}}=$ Kruskal-Wallis $\boldsymbol{H}$-value.

\begin{tabular}{lcccc}
\hline \hline & \multicolumn{2}{c}{ Percent Time Spent Per Behavior } & & \\
\cline { 2 - 3 } Behavior & Paired & Unpaired & Test Statistic Value & $P$-value \\
\hline Forage & $20.3 \pm 2.2$ & $12.0 \pm 1.1$ & $11.39 \mathrm{~kW}$ & $<0.001$ \\
Rest & $31.2 \pm 2.5$ & $35.5 \pm 1.5$ & 2.93 & 0.088 \\
Maintenance & $22.9 \pm 1.7$ & $25.0 \pm 1.1$ & 2.46 & 0.117 \\
Locomotion & $13.1 \pm 1.2$ & $15.8 \pm 0.9$ & 0.001 & 0.972 \\
Alert & $10.8 \pm 0.9$ & $10.9 \pm 0.6$ & 1.08 & 0.299 \\
Social & $1.8 \pm 0.4$ & $0.7 \pm 0.1$ & $9.43^{\mathrm{KW}}$ & 0.002 \\
\hline
\end{tabular}


tids (Ashcroft 1976; Rohwer and Anderson 1988; Oring and Sayler 1992), males allocated more time to vigilance and less time to foraging during the peak breeding season compared to other months, and time allocated to courtship and mate defense peaked between November and March. However, contrary to our prediction, female foraging effort was not higher during the peak nesting season. Our test may be constrained by limited sample size; but it is more likely that our results reflect that the protracted nesting season means a significant proportion of females may not be nesting at any single point in time. Such asynchrony coupled with our inability to assign birds to a life-history stage (i.e., breeding or non-breeding) when they were observed would weaken our ability to detect a difference. Also, females may increase intake rate and feeding efficiency, or shift diet to more nutrient-rich food sources during the nesting period (Krapu and Reinecke 1992), thereby increasing nutrient intake without increasing time spent foraging.

Our population-level characterization of an extended breeding season for Hawaiian Ducks is consistent with the generalization that species and populations occupying lower latitudes typically have longer breeding seasons than their northern-breeding counterparts (Ricklefs 1966; Immelmann 1971; Johnson et al. 1992). For example, Mallards breeding in temperate and subarctic regions have a predictable and concentrated nest initiation period that generally occurs during a 3-month period from April through June (Drilling et al. 2002), whereas Laysan Ducks, a non-migratory species occupying subtropical latitudes, have a nesting season typically ranging from 4 to 8 months during the spring and summer (Moulton and Weller 1984; Reynolds et al. 2007; Walters and Reynolds 2013). Yet, while Laysan Ducks and other subtropical dabbling ducks (e.g., Mottled Ducks ( $A$. fulvigula)) have been documented nesting during most or all months of the year, they do not necessarily do so within the same year and instead exhibit considerable annual flexibility in the timing and duration of nest initiation to coincide with favorable climate and resource conditions (e.g., food, habitat; Sorenson 1992; Reynolds et al. 2007; Bielefeld et al. 2010; Walters and Reynolds 2013). We did not detect a relationship between rainfall and nesting activity in our study; however, peak nesting (SeptemberMay) was broadly centered over the typical wet season (November-April). Nevertheless, the occurrence of year-round nesting indicates the baseline environmental requirements (e.g., climate and resource conditions) for breeding are met throughout the year in northern Kaua'i. However, it is possible that key vital rates (e.g., nest success, clutch size, duckling survival) vary by month or season.

Despite the peak in apparent nesting activity between September and May, and unlike temperate and Arctic-breeding Anas species, the percentage of paired female Hawaiian Ducks remained high throughout the year $(62 \%)$, suggesting Hawaiian Ducks maintain extended seasonal pair bonds. Evidence from other studies suggests that Laysan Ducks, White-cheeked Pintails ( $A$. bahamensis), and sedentary populations of Mallards may quickly re-pair after molt and brood rearing or remain paired year-round (Moulton and Weller 1984; Mjelstad and Saetersdal 1990; Sorenson 1992; Reynolds 2002). Extended seasonal pair status may give females increased dominance rank and access to higher quality resources for a greater proportion of the year (Paulus 1983; Heitmeyer 1985), and paired birds in our study foraged more than unpaired birds throughout the year.

Compared to continental Mallards and Mottled Ducks in North America, Hawaiian Ducks generally allocated less of their diurnal activity budget to foraging (10$18 \%)$ and did not exhibit as strong a seasonal shift in time spent foraging. For example, Paulus (1984; 1988b) estimated that Mottled Ducks in Louisiana spend $39 \%$ and $55 \%$ of their time feeding during non-breeding and breeding seasons, respectively; and Mallards generally allocate $30-40 \%$ of their time feeding during winter (Jorde 1981; Johnson and Rohwer 2000) 
and 40-64\% during the breeding season (Kaminski and Prince 1981; Dugger and Petrie 2000). The relatively large disparity in overall foraging time and lack of strong seasonal adjustments in activity budgets of Hawaiian Ducks suggest they have lower daily and seasonal energy demands associated with sedentary, as opposed to migratory, behavior (McLandress and Raveling 1981; Miller 1985; Paulus 1988a) and the milder year-round climate (Hickey and Titman 1983; Paulus 1988b; Root 1988). It also is possible that Hawaiian Ducks allocate a greater amount of time to nocturnal foraging activities overall, as is the case with Laysan Ducks (Reynolds 2002), or at certain times of the year corresponding with energetically costly life history events. Hawaiian Ducks can be active at night (B. D. Dugger, pers. obs.); however, our sampling efforts were restricted to crepuscular and diurnal hours, and the extent of such nocturnal activity is unknown.

Management activities at Hanalei NWR aim to provide resources (e.g., food, cover) for multiple life history stages of Hawaiian Ducks concurrently throughout the year. Our results suggest this strategy is largely appropriate for certain aspects of management. For example, given that peak nesting occurs over a 9-month period and ducklings attain flight at 2 months of age, the availability of high quality brood-rearing cover and foraging habitat for nesting females is probably important throughout the entire year. Similarly, non-native predator control is probably beneficial year-round; though control efforts may have to differ according to life-history stage (e.g., egg, duckling, adult) and the particular predator threat. However, our results also suggest refinements in the timing of certain management activities. We recommend managing nesting habitat so that it is available during September through May, a period most closely tied with nest initiation. If the goal is to avoid nest disturbance and potential abandonment in upland habitat, we recommend conducting upland habitat maintenance and restoration actions during June, July, and August.
ACKNOWLEDGMENTS

Funding and in-kind support was provided by U.S. Fish and Wildlife Service Ecological Services and Region 1 Migratory Birds, Oregon State University, the Mace Watchable Wildlife endowment, and Kaua'i NWR Complex. We greatly appreciate the support and cooperation provided by A. P. Marshall and the Kaua' $i$ NWR Complex, particularly S. N. Smith, M. W. Mitchell, and C. C. Smith. We thank C. J. Billat, M. E. Dalton, J. L. Harris, W. M. Taylor, and K. B. Valier for field assistance, and Hanalei taro farmers for their cooperation. We thank J. Van Sickle for providing statistical advice, and S. M. Haig and A. T. Morzillo for providing helpful comments on earlier drafts of this manuscript. We are grateful to two anonymous reviewers for valuable comments and suggestions that improved this manuscript. No birds were captured or handled during this study. All applicable ethical guidelines for the use of birds in research have been followed, including those presented in the Ornithological Council's "Guidelines to the Use of Wild Birds in Research" (Fair et al. 2010).

\section{Literature Cited}

Alisauskas, R. T. and C. D. Ankney. 1992. The cost of egg laying and its relationship to nutrient reserves in waterfowl. Pages 30-61 in Ecology and Management of Breeding Waterfowl (B. D. J. Batt, A. D. Afton, M. G. Anderson, C. D. Ankney, D. H. Johnson, J. A. Kadlec and G. L. Krapu, Eds.). University of Minnesota Press, Minneapolis, Minnesota.

Altmann, J. 1974. Observational study of behavior sampling methods. Behaviour 49: 227-267.

Arzel, C., J. Elmberg and M. Guillemain. 2007. A flyway perspective of foraging activity in Eurasian Greenwinged Teal, Anas crecca crecca. Canadian Journal of Zoology 85: 81-91.

Ashcroft, R. E. 1976. A function of the pairbond in the Common Eider. Wildfowl 27: 101-105.

Ashkenazie, S. and U. N. Safriel. 1979. Time-energy budget of the Semipalmated Sandpiper Calidris pusilla at Barrow, Alaska. Ecology 60: 783-799.

Baldassarre, G. A. 2014. Ducks, geese, and swans of North America. Johns Hopkins University Press, Baltimore, Maryland.

Baldassarre, G. A., S. L. Paulus, A. Tamisier and R. D. Titman. 1988. Workshop summary: techniques for timing activity of wintering waterfowl. Pages 181-190 in Waterfowl in Winter (M. W. Weller, Ed.). University of Minnesota Press, Minneapolis, Minnesota.

Batt, B. D., A. D. Afton, M. G. Anderson, C. D. Ankney, D. H. Johnson, J. A. Kadlec and G. L. Krapu (Eds.). 1992. Ecology and management of breeding waterfowl. University of Minnesota Press, Minneapolis, Minnesota.

Bielefeld, R. R., M. G. Brasher, T. E. Moorman and P. N. Gray. 2010. Mottled Duck (Anas fulvigula). No. 81 in The Birds of North America Online (A. F. Poole, Ed.). Cornell Lab of Ornithology, Ithaca, New York. http://bna.birds.cornell.edu/bna/species/081/, accessed 10 October 2013. 
BirdLife International. 2017. Anas wyvilliana (amended version of 2016 assessment). In International Union for Conservation of Nature (IUCN). The IUCN Red List of Threatened Species, v. 2018-1. http://www. iucnredlist.org, accessed 6 November 2018.

Caraco, T. 1979. Time budgeting and group size: a theory. Ecology 60: 611-617.

Coffman, W. P. and C. L. de la Rosa. 1998. Taxonomic composition and temporal organization of tropical and temperate species assemblages of lotic Chironomidae. Journal of the Kansas Entomological Society 71: 388-406.

Drilling, N., R. D. Titman and F. McKinney. 2002. Mallard (Anas platyrhynchos). No. 658 in The Birds of North America Online (A. F. Poole and F. B. Gill, Eds.). Cornell Lab of Ornithology, Ithaca, New York. http://bna.birds.cornell.edu/bna/species/658/, accessed 10 October 2013.

Dugger, B. D. and M. J. Petrie. 2000. Geographic variation in foraging patterns of pre-incubating female Mallards. Canadian Journal of Zoology 78: 2240-2243.

Engilis, A., Jr., K. J. Uyehara and J. G. Giffin. 2002. Hawaiian Duck (Anas wyvilliana). No. 694 in The Birds of North America Online (A. F. Poole and F. B. Gill, Eds.). Cornell Lab of Ornithology, Ithaca, New York. http://bna.birds.cornell.edu/bna/species/694, accessed 10 October 2013.

Fair, J., E. Paul and J. Jones (Eds.). 2010. Guidelines to the use of wild birds in research. Ornithological Council, Washington, D.C.

Fowler, A. C., J. M. Eadie and A. Engilis. 2009. Identification of endangered Hawaiian ducks (Anas wyvilliana), introduced North American mallards ( $A$. platyrhynchos) and their hybrids using multilocus genotypes. Conservation Genetics 10: 1747-1758.

Giffin, J. G. 1983. (1) Abundance and distribution of koloa on the Island of Hawaii. (2) Movements, survival, reproductive success and habitat of koloa on the Island of Hawaii. Unpublished report, PittmanRobertson Project No W-18-R-7 and W-18-R-8, Job No R-III-H, Hawaii Division of Fish and Game, Honolulu, Hawaii.

Goldstein, D. L. 1988. Estimates of daily energy expenditures in birds: the time-energy budget as an integrator of laboratory and field studies. American Zoologist 28: 829-844.

Gollop, J. B. and W. H. Marshall. 1954. A guide for aging duck broods in the field v. 14NOV97. Unpublished report, Mississippi Flyway Council Technical Section, Northern Prairie Wildlife Research Center, Jamestown, North Dakota. http://archive.is/ fpqWk\#selection-593.5-597.5, accessed 30 December 2018.

Hails, C. J. 1982. A comparison of tropical and temperate aerial insect abundance. Biotropica 14: 310-313.

Heitmeyer, M. E. 1985. Wintering strategies of female mallards related to dynamics of lowland hardwood wetlands in the upper Mississippi Delta. Ph.D. Dissertation, University of Missouri, Columbia.

Hickey, T. E. and R. D. Titman. 1983. Diurnal activity budgets of Black Ducks during their annual cycle in
Prince Edward Island. Canadian Journal of Zoology 61: 743-749.

Immelmann, K. 1971. Ecological aspects of periodic reproduction. Avian Biology 1: 341-389.

Jacobsen, D., C. Cressa, J. M. Mathooko and D. Dudgeon. 2008. Macroinvertebrates: composition, life histories and production. Pages 65-105 in Tropical Stream Ecology (D. Dudgeon, Ed.). Academic Press, San Francisco, California.

Johnsgard, P. A. 1965. Handbook of waterfowl behavior. Cornell University Press, Ithaca, New York.

Johnson, D. H., J. D. Nichols and M. D. Schwartz. 1992. Population dynamics of breeding waterfowl. Pages 446-485 in Ecology and Management of Breeding Waterfowl (B. D. J. Batt, A. D. Afton, M. G. Anderson, C. D. Ankney, D. H. Johnson, J. A. Kadlec and G. L. Krapu, Eds.). University of Minnesota Press, Minneapolis, Minnesota.

Johnson, W. P. and F. C. Rohwer. 2000. Foraging behavior of green-winged teal and mallards on tidal mudflats in Louisiana. Wetlands 20: 184-188.

Jónsson, J. E. and A. D. Afton. 2009. Time budgets of Snow Geese Chen caerulescens and Ross's Geese Chen rossii in mixed flocks: implications of body size, ambient temperature and family associations. Ibis 151 : 134-144.

Jorde, D. G. 1981. Winter and spring staging ecology of mallards in south central Nebraska. M.S. Thesis, University of North Dakota, Grand Forks.

Kaminski, R. M. and H. H. Prince. 1981. Dabbling duck activity and foraging responses to aquatic macroinvertebrates. Auk 98: 115-126.

Karr, J. R. 1976. Seasonality, resource availability, and community diversity in tropical bird communities. American Naturalist 110: 973-994.

Krapu, G. L. and K. J. Reinecke. 1992. Foraging ecology and nutrition. Pages 1-29 in Ecology and Management of Breeding Waterfowl (B. D. J. Batt, A. D. Afton, M. G. Anderson, C. D. Ankney, D. H. Johnson, J. A. Kadlec and G. L. Krapu, Eds.). University of Minnesota Press, Minneapolis, Minnesota.

Lavretsky, P., A. Engilis, J. M. Eadie and J. L. Peters. 2015. Genetic admixture supports an ancient hybrid origin of the endangered Hawaiian duck. Journal of Evolutionary Biology 28: 1005-1015.

Lorenz, K. Z. 1951. Comparative studies on the behavior of Anatinae. Avicultural Magazine 57: 157-182.

Losito, M. P., R. E. Mirarchi and G. A. Baldassarre. 1989. New techniques for time-activity studies of avian flocks in view-restricted habitats. Journal of Field Ornithology 60: 388-396.

Malachowski, C. P. 2013. Hawaiian Duck (Anas wyvilliana) behavior and response to wetland habitat management at Hanalei National Wildlife Refuge on Kaua'i. M.S. Thesis, Oregon State University, Corvallis.

McKinney, F. 1965. The comfort movements of Anatidae. Behaviour 25: 120-220.

McLandress, M. R. and D. G. Raveling. 1981. Hyperphagia and social behavior of Canada Geese prior to spring migration. Wilson Bulletin 93: 310-324. 
Miller, M. R. 1985. Time budgets of Northern Pintails wintering in the Sacramento Valley, California. Wildfowl 36: 53-64.

Mjelstad, H. and M. Saetersdal. 1990. Reforming of resident Mallard pairs Anas platyrhynchos, rule rather than exception? Wildfowl 41: 150-151.

Moulton, D. W. and M. W. Weller. 1984. Biology and conservation of the Laysan Duck (Anas laysanensis). Condor 86: 105-117.

National Climate Data Center (NCDC). 2017. Climate data online. NCDC, Washington, D.C. http://www. ncdc.noaa.gov/, accessed 1 August 2017.

Newton, I. 2008. The migration ecology of birds. Academic Press, San Diego, California.

Oring, L. W. and R. D. Sayler. 1992. The mating systems of waterfowl. Pages 190-213 in Ecology and Management of Breeding Waterfowl (B. D. J. Batt, A. D. Afton, M. G. Anderson, C. D. Ankney, D. H. Johnson, J. A. Kadlec and G. L. Krapu, Eds.). University of Minnesota Press, Minneapolis, Minnesota.

Paulus, S. L. 1983. Dominance relations, resource use, and pairing chronology of Gadwalls in winter. Auk 100: 947-952.

Paulus, S. L. 1984. Behavioral ecology of mottled ducks in Louisiana. Ph.D. Dissertation, Auburn University, Auburn, Alabama.

Paulus, S. L. 1988a. Time-activity budgets of nonbreeding Anatidae: a review. Pages 135-152 in Waterfowl in Winter (M. W. Weller, Ed.). University of Minnesota Press, Minneapolis, Minnesota.

Paulus, S. L. 1988b. Time-activity budgets of mottled ducks in Louisiana in winter. Journal of Wildlife Management 52: 711-718.

R Development Core Team. 2017. R: a language and environment for statistical computing v. 3.4.1. R Foundation for Statistical Computing, Vienna, Austria. http:/ / www.R-project.org/, accessed 30 June 2017.

Ramsey, F. L. and D. W. Schafer. 2002. The statistical sleuth: a course in methods of data analysis, 2nd ed. Duxbury Press, Pacific Grove, California.

Reynolds, M. H. 2002. The foraging ecology, habitat use, and population dynamics of the Laysan teal (Anas laysanensis). Ph.D. Dissertation, Virginia Polytechnic Institute and State University, Blacksburg.

Reynolds, M. H., L. H. Crampton and M. S. Vekasy. 2007. Laysan Teal Anas laysanensis nesting phenol- ogy and site characteristics on Laysan Island. Wildfowl 57: 54-67.

Richardson, F. and J. Bowles. 1964. A survey of the birds of Kauai, Hawaii. B.P. Bishop Museum Bulletin 227: 1-51.

Ricklefs, R. E. 1966. The temporal component of diversity among species of birds. Evolution 20: 235-242.

Rohwer, F. C. and M. G. Anderson. 1988. Female-biased philopatry, monogamy, and the timing of pair formation in migratory waterfowl. Current Ornithology 5: 187-221.

Root, T. 1988. Energy constraints on avian distributions and abundances. Ecology 69: 330-339.

Sorenson, L. G. 1992. Variable mating system of a sedentary tropical duck - the White-cheeked Pintail (Anas bahamensis bahamensis). Auk 109: 277-292.

Stouffer, P. C., E. I. Johnson and R. O. Bierregaard, Jr. 2013. Breeding seasonality in central Amazonian rainforest birds. Auk 130: 529-540.

Stutchbury, B. J. M. and E. S. Morton. 2001. Behavioral ecology of tropical birds. Academic Press, San Diego, California.

Swedberg, G. E. 1967. The koloa: a preliminary report on the life history and status of the Hawaiian Duck (Anas wyvilliana). Unpublished report, Department of Land and Natural Resources, Honolulu, Hawai'i.

U.S. Fish and Wildlife Service. 2011. Revised recovery plan for Hawaiian waterbirds, 2nd revision. Unpublished report, U.S. Department of Interior, Fish and Wildlife Service, Portland, Oregon.

Uyehara, K. J., A. Engilis, Jr. and B. D. Dugger. 2008. Wetland features that influence occupancy by the endangered Hawaiian Duck. Wilson Journal of Ornithology 120: 311-319.

Walters, J. R. and M. H. Reynolds. 2013. Experimental reintroduction reveals novel life-history variation in Laysan Ducks (Anas laysanensis). Auk 130: 573-579.

Weller, M. W. 1980. The island waterfowl. Iowa State University Press, Ames, Iowa.

Wikelski, M., M. Hau and J. C. Wingfield. 2000. Seasonality of reproduction in a neotropical rain forest bird. Ecology 81: 2458-2472.

Williams, T. D. 2012. Physiological adaptations for breeding in birds. Princeton University Press, Princeton, New Jersey.

Wyndham, E. 1986. Length of birds' breeding seasons. American Naturalist 128: 155-164. 